\title{
In Vitro Propagation and Detection of Somaclonal Variation in Phalaenopsis gigantea as Affected by Chitosan and Thidiazuron Combinations
}

\author{
Samira Samarfard and Mihdzar A. Kadir ${ }^{1}$ \\ Department of Agriculture Technology, Faculty of Agriculture, Universiti \\ Putra Malaysia, 43400, Serdang, Selangor, Malaysia
}

Saleh B. Kadzimin

Department of Crop Science, Faculty of Agriculture, Universiti Putra Malaysia, 43400, Serdang, Selangor, Malaysia

Halimi M. Saud

Department of Agriculture Technology, Faculty of Agriculture, Universiti Putra Malaysia, 43400, Serdang, Selangor, Malaysia

Seyed Ali Ravanfar

Institute of Tropical Agriculture, Laboratory of Plantation Crops, Universiti Putra Malaysia Serdang, Selangor Darul Ehsan, Malaysia

\section{Mahmoud Danaee \\ Department of Agriculture Technology, Faculty of Agriculture, Universiti Putra Malaysia, 43400, Serdang, Selangor, Malaysia}

Additional index words. chitosan, intersimple sequence repeats, Phalaenopsis gigantea, protocorm-like bodies, thidiazuron, Vacin and Went medium

\begin{abstract}
Protocorm-like bodies (PLBs) multiplication is one of the most preferable in vitro methods to increase the number of orchids that produce very few seeds or seeds that are not able to germinate. In the present study the effects of chitosan and thidiazuron (TDZ) combinations on multiplication, differentiation, and genetic stability of Phalaenopsis gigantea PLBs were investigated using different media. Initial PLBs were cultured in solid New Dogashima (ND) medium and Vacin and Went (VW) medium supplemented with different concentrations of chitosan $\left(0,5,10,15,20\right.$, and $\left.25 \mathrm{mg} \cdot \mathrm{L}^{-1}\right)$ and TDZ $(0,0.1$, and $0.5 \mathrm{mg} \cdot \mathrm{L}^{-1}$ ). The highest mean number of PLBs (353 PLBs) was observed in ND medium with $10 \mathrm{mg} \cdot \mathrm{L}^{-1}$ chitosan and $0.1 \mathrm{mg} \cdot \mathrm{L}^{-1} \mathrm{TDZ}$ combination after 20 weeks of culture. Some PLBs differentiated into mature PLBs with a profusion of leaves on the apical region, and tiny plantlets started to develop after 10 weeks of culture. The highest mean number of shoots was observed in VW supplemented with $10 \mathrm{mg} \cdot \mathrm{L}^{-1}$ chitosan and $0.5 \mathrm{mg} \cdot \mathrm{L}^{-1}$ TDZ (16 shoots). Intersimple sequence repeat (ISSR) markers were used to determine the genetic fidelity among mother plant and PLBs obtained from each subculture stage of solid ND medium supplemented with $10 \mathrm{mg} \cdot \mathrm{L}^{-1}$ chitosan and $0.1 \mathrm{mg} \cdot \mathrm{L}^{-1} \mathrm{TDZ}$ (the optimal treatment for PLB proliferation). Dissimilarity of $5 \%$ occurred between the mother plant and PLBs obtained after 16 weeks of culture. The range in the similarity coefficient varied from 0.80 to 1.0 , and only $20 \%$ dissimilarity occurred between mother plant and PLBs after 20 weeks of culture.
\end{abstract}

The Orchidaceae is one of the most diverse of flowering plant families, containing 25,000 species from more than 800 identified genera (Thammasiri, 2002). The genus Phalaenopsis

Received for publication 15 July 2013. Accepted for publication 11 Nov. 2013.

We are grateful to Dr. Sang Mi Eum from the Department of Life Science, Ewha Womans University, Seoul, Korea, and Dr. Soo-Yong Kim Co-director of Korea-Costa Rica Biodiversity Research Center, for generously sharing their experiences and time in assisting this research.

${ }^{1}$ To whom reprint requests should be addressed; e-mail Mihdzar@gmail.com.
Species multiplication is naturally performed through the configuration of new buds induced at the bases of mature plants. However, the procedure is very rare as a result of the low number of new buds initiated by a mature plant (Shu-guo, 2008). Tissue culture techniques have been used for rapid propagation on a large scale as well as for conservation purposes (Murdad et al., 2006). Orchid propagation through PLBs multiplication is one of the most preferable in vitro methods used in different orchid genera as a result of the great number of PLBs that can be obtained in a short period of time. Protocorm is the earliest structure formed in embryo development during seed germination (Ishii et al., 1998). PLB multiplication is often applied to increase the number of orchids that are not able to germinate well or produce very few seeds. PLBs are also highly targeted tissues for genetic transformation studies in orchids as a result of its rapid proliferation and capability to regenerate into complete plantlets (Liau et al., 2003; Sreeramanan et al., 2008). The enhancement of multiplication, total yield, and successive maturity into plantlets without much mutation are most preferred (Pornpienpakdee et al., 2010). Different explants, combinations, and concentrations of plant growth regulators have been significant factors for in vitro multiplication of orchids (Arditti and Ernest, 1993).

Chitosan is an environmentally friendly carbohydrate that has been reported to stimulate growth of several plant species, including orchids (Nge et al., 2006). TDZ is the most compelling cytokinin for enhancing PLB proliferation and subsequent shoot regeneration in Phalaenopsis species (Ernst, 1994). Phalaenopsis gigantea is inherently difficult to propagate. Hence, the use of chitosan as a supplement in growth media could provide an alternative means for in vitro mass multiplication of PLBs. This study was therefore designed to evaluate the influence of chitosan and TDZ combination on PLB proliferation of Phalaenopsis gigantea. In the case of Phalaenopsis gigantea, somaclonal variation may result in changes in the morphological properties of flowers including color and shape. The occurrence of somaclonal variations during tissue culture largely depends on media composition, rate of multiplication, the type of explants, formation of adventitious shoots, the culture period, and plant genotype (Cote et al., 1993). Molecular markers have been recently used as conventional tools for assessment of genetic stability of in vitro products. ISSR markers have also been used to assess genetic fidelity in several regenerated plants including banana (Lakshmanan et al., 2007), Camellia sinensis (Devarumath et al., 2002), and Swertia chirayita (Joshi and Dhawan, 2007). The present study was conducted to verify the genetic stability of in vitro PLBs produced during subculture of Phalaenopsis gigantea using ISSR markers.

\section{Materials and Methods} of this species (Rodrigues and Kumar, 2009). The species has the capability of producing attractive hybrids (Niknejad et al., 2011).
Plant materials. Young leaves from an in vitro mother plant were used for initial 
induction of PLBs. The leaf tip segments ( $1.5 \mathrm{~cm}$ in length) were excised and cultured on semisolid ND medium (NDM) (Tokuhara and Mii, 1993, 1998) supplemented with $0.1 \mathrm{mg} \cdot \mathrm{L}^{-1} \mathrm{TDZ}$ and $1.0 \mathrm{mg} \cdot \mathrm{L}^{-1}$ naphthalene acetic acid (NAA). The protocol was selected based on an earlier report on Phalaenopsis gigantea (Niknejad et al., 2011). The cultures were placed under a $16-\mathrm{h}$ photoperiod at an irradiance of $30 \mu \mathrm{mol} \cdot \mathrm{m}^{-2} \cdot \mathrm{s}^{-1}$ and temperature of $25 \pm 2{ }^{\circ} \mathrm{C}$. The earliest morphological sign of PLB formation appeared as swellings on the adaxial side of leaf segments within 4 to 6 weeks of culture; small round bodies (small initial PLBs) were transferred to hormone free NDM and used as plant material (Fig. 1A).

Chitosan and media preparation. PLB multiplication of Phalaenopsis gigantea was investigated using solid VW medium (Vacin and Went, 1949) and NDM supplemented with chitosan $\left(0,5,10,15,20\right.$, and $\left.25 \mathrm{mg} \cdot \mathrm{L}^{-1}\right)$ in combination with TDZ at concentrations of 0 , 0.1 , and $0.5 \mathrm{mg} \cdot \mathrm{L}^{-1}$. The range of TDZ and chitosan was selected based on early reports on Phlaenopsis gigantea proliferation and the effects of chitosan on orchid multiplication (Niknejad, 2009; Sopalun et al., 2010). Chitosan powder labeled as low molecular weight with a $75 \%$ degree of deacetylation (Sigma, St. Louis, MO) was selected for the preparation of stock solution. The powder was dissolved and stirred in $1 \%$ acetic acid and heated to $35^{\circ} \mathrm{C}$ with constant agitation for $24 \mathrm{~h}$. The $\mathrm{pH}$ of the stock solution was adjusted to 5.7 using sodium hydroxide solution $(2.0 \mathrm{M})$ and the solution was stirred for $4 \mathrm{~h}$. Macronutrients and micronutrients of
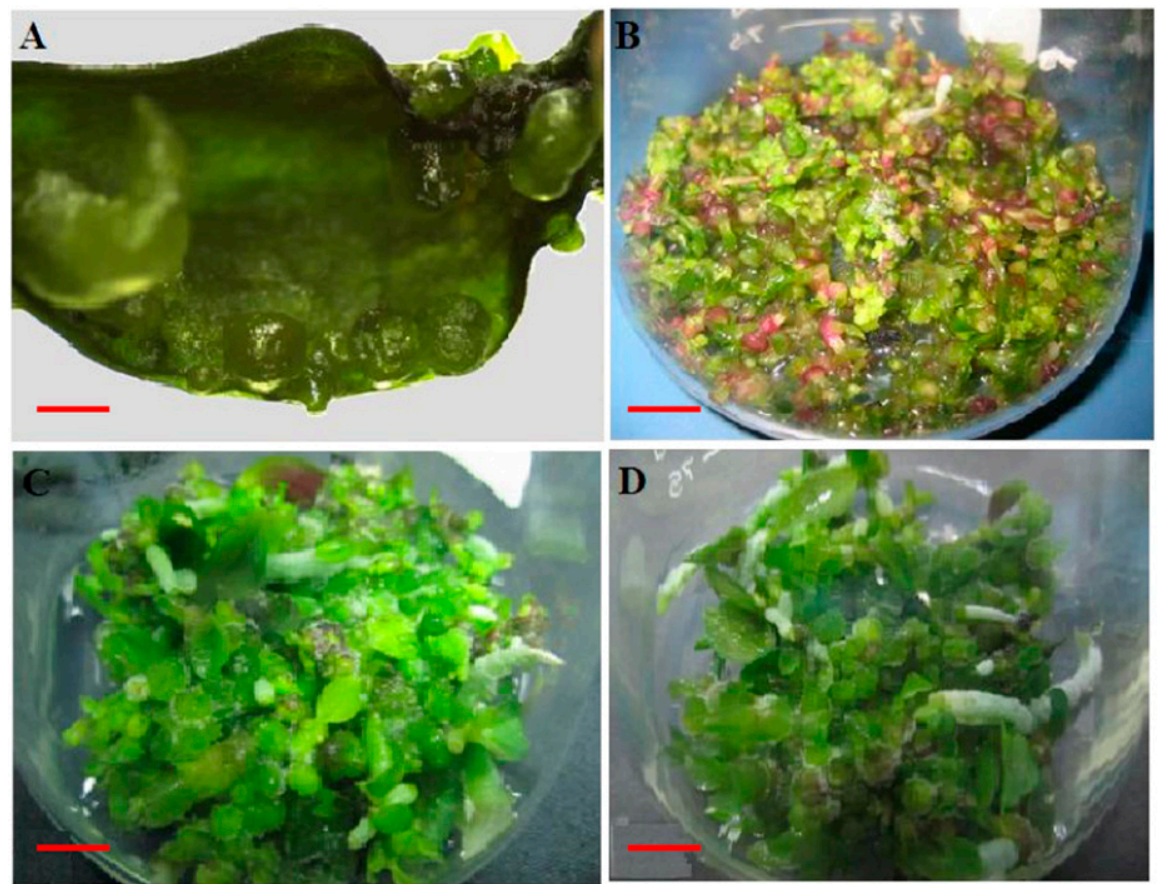

Fig. 1. In vitro protocorm-like body (PLB) multiplication of Phalaenosis gigantea. (A) PLB Induction from leaf segment of donor plant after 4 weeks of cultivation $(\mathrm{bar}=2 \mathrm{~mm}$ ). (B) PLBs obtained after 20 weeks of in vitro cultivation in solid New Dogashima medium (NDM) supplemented with $10 \mathrm{mg} \cdot \mathrm{L}^{-1}$ chitosan and $0.1 \mathrm{mg} \cdot \mathrm{L}^{-1}$ of thidiazuron (TDZ) $(\mathrm{bar}=20 \mathrm{~mm}$ ). (C) Shoot formation after 20 weeks in Vacin and Went (VW) at $10 \mathrm{mg} \cdot \mathrm{L}^{-1}$ chitosan and $0.5 \mathrm{mg} \cdot \mathrm{L}^{-1} \mathrm{TDZ}$. (D) Shoot formation in VW at $20 \mathrm{mg} \cdot \mathrm{L}^{-1}$ chitosan $(\mathrm{bar}=20 \mathrm{~mm})$.

the agar media (VW and NDM) were prepared and each component was dissolved and mixed together before making up the volume with distilled water. The medium $\mathrm{pH}$ was adjusted to 5.7 with $1 \mathrm{M} \mathrm{NAOH}$ or HCL, and the media were solidified with Gelrite $0.2 \%$ $(\mathrm{w} / \mathrm{v})$. The media distributed in Erlenmeyer flasks $(200 \mathrm{~mL})$ were autoclaved for $20 \mathrm{~min}$ at $121^{\circ} \mathrm{C}$ and 15 psi.

Proliferation conditions. To study the growth and differentiation of $P$. gigantea PLBs, five PLBs ( 0.25 to $0.3 \mathrm{~g}$ ) were cultured in Erlenmeyer flasks $(200 \mathrm{~mL})$ containing $50 \mathrm{~mL}$ of agar medium supplemented with inations of chitosan $(0,5,10,15,20$, and $\left.25 \mathrm{mg} \cdot \mathrm{L}^{-1}\right)$ and TDZ $\left(0,0.1\right.$, and $\left.0.5 \mathrm{mg} \cdot \mathrm{L}^{-1}\right)$. Cultures were kept at $25 \pm 2{ }^{\circ} \mathrm{C}$ under 16 -h $30 \mu \mathrm{mol} \cdot \mathrm{m}^{-2} \cdot \mathrm{s}^{-1}$ per day and maintained for 5 months.

Experimental design and statistical analysis. The study on in vitro multiplication of PLB was laid out in a factorial combination of treatments based on a randomized complete block design. The recorded data were analyzed using the analysis of variance and means were separated using Duncan's new multiple nge test using NTSYS-PC 2.02. All statistical data were tested at the 5\% level of significance for comparison between treatthis study, eight experimencombination and the experiment consisted of three replicates. The results are presented as means $\pm \mathrm{SE}$.

DNA extraction. Leaves of in vitro mother plant (MP) were used for the isolation of

HortScience Vol. 49(1) JanUary 2014 genomic DNA and polymerase chain reaction (PCR) amplification. To study the genetic stability among MP and regenerated PLBs after 4, 8, 12, 16, and 20 weeks of culture, designated as S1, S2, S3, S4, and S5, respectively, the PLBs obtained at the end of each subculturing were randomly used for genomic DNA isolation. Samples from MP, S1, S2, S3 S4, and S5 were first washed with tap water and sterilized in sodium hypochlorite $\left(10 \% \mathrm{v} / \mathrm{v}\right.$ Clorox $\left.^{\circledR}\right)$ solution for $5 \mathrm{~min}$. The PLBs were rinsed three times with distilled water, wrapped with aluminum foil, and stored at $-80{ }^{\circ} \mathrm{C}$ for genomic DNA extraction. DNA extraction was carried out using the cetyltrimethylammonium bromide method (Doyle and Doyle, 1990) with minor modifications. Quality and quantity of DNA was monitored by spectrophotometry and gel inspection.

PCR amplification and analysis of ISSR data. To optimize PCR amplification conditions, the experiment was carried out in a total volume of $25 \mu \mathrm{L}$ including DNA templates $\left(20,30,40\right.$, and $\left.50 \mathrm{ng} \cdot \mu \mathrm{L}^{-1}\right)$, ISSR primers $(1.2 \mu \mathrm{M})$, DreamTaq ${ }^{\mathrm{TM}}$ Green PCR Master Mix (Fermentas, Inc., Hanover, MD), and $10.4 \mu \mathrm{L}$ nuclease-free water. A total of 10 ISSR primers were used for initial screening with the mother plant of Phalaenopsis gigantea but only eight ISSR primers gave clear and reproducible bands. Amplification was performed in a PTC-100 programmable Thermal Controller (MJ Research Inc.). The amplification reaction consisted of an initial denaturation step at $94^{\circ} \mathrm{C}$ for $5 \mathrm{~min}$, followed by 35 cycles of denaturation at $94^{\circ} \mathrm{C}$ for $30 \mathrm{~s}$, annealing temperature at 54.2 to $60.5^{\circ} \mathrm{C}$ for $90 \mathrm{~s}$ (Table 1), and continued at $72{ }^{\circ} \mathrm{C}$ for $90 \mathrm{~s}$ and the final extension was adjusted at $72{ }^{\circ} \mathrm{C}$ for $5 \mathrm{~min}$. The amplified products were separated on $1.5 \%(\mathrm{w} / \mathrm{v})$ agarose gels applied with $1 \times$ TAE buffer at $80 \mathrm{~V}$ for $60 \mathrm{~min}$, stained with $2 \mathrm{mg} \cdot \mathrm{L}^{-1}$ ethidium bromide for $5 \mathrm{~min}$, destained in sterilized distilled water for $3 \mathrm{~min}$, and visualized under ultraviolet light and photographed. The molecular size of amplified PCR products was estimated using a 1-kb DNA ladder (Fermentas, Inc.). The digital image files were analyzed using UVIDoc software Version 99.01 (UVItech Limited, U.K.) and fragment sizes were estimated based on the DNA ladder. All reactions were repeated three times. Only well-separated bands with high intensity were scored as present or absent for ISSR markers. The scoring of bands was done as 1 for presence and 0 for the absence of DNA bands in the gel. Electrophoretic DNA bands of low visual intensity that could not be readily differentiated as present or absent were considered ambiguous markers and were not scored. The distance matrix and dendrogram were constructed using the NTSYS-Pc Version 2.1 software package (Rohlf, 1993). Similarity coefficient was used to construct the dendrogram using the unweighted pair group method with arithmetic average and the sequential, hierarchical and nested clustering routine in the NTSYS program. The genetic stability was evaluated by calculating the Jaccard's 
Table 1. Total number and size range of amplified ISSR bands and number of polymorphic fragments induced by MP and PLBs achieved from different subcultures of optimum treatment.

\begin{tabular}{|c|c|c|c|c|c|c|}
\hline Primer & Sequence $\left(5^{\prime}-3^{\prime}\right)$ & Number of amplified band & $\begin{array}{c}\text { Ranges } \\
\text { Low-high }\end{array}$ & Number of polymorphic band & $\mathrm{TM}\left({ }^{\circ} \mathrm{C}\right)$ & Polymorphism (\%) \\
\hline T05 & CGTT(GT)7 & 13 & $209-2000$ & 2 & 60.2 & 15.4 \\
\hline UBC 842 & (GA)8YG5 & 6 & $912-3742$ & 0 & 60.2 & 0.0 \\
\hline UBC 812 & (GA) $8 \mathrm{~A}$ & 5 & $384-2329$ & 0 & 54.8 & 0.0 \\
\hline I65 & (AG) $8 \mathrm{CC}$ & 11 & $800-3074$ & 3 & 61.8 & 27.3 \\
\hline UBC834 & (AG) $8 \mathrm{CT}$ & 9 & $405-2671$ & 2 & 59.1 & 22.2 \\
\hline I4 & (AC) $8 \mathrm{AG}$ & - & - & - & 55.02 & - \\
\hline Total & & 67 & & 11 & & \\
\hline
\end{tabular}

$\mathrm{MP}=$ mother plant; $\mathrm{PLBs}=$ protocorm-like bodies; $\mathrm{TM}=$ temperature.

similarity coefficient for pairwise comparisons based on the proportion of shared bands produced by the primers.

\section{Results}

Effect of chitosan and TDZ combinations on PLB proliferation. Initial PLBs with smooth-surfaced, small, and round greenish bodies were cultured on semisolid NDM and VW media containing different concentrations of chitosan $\left(0,5,10,15,20\right.$, and $\left.25 \mathrm{mg} \cdot \mathrm{L}^{-1}\right)$ and TDZ $\left(0,0.1\right.$, and $\left.0.5 \mathrm{mg} \cdot \mathrm{L}^{-1}\right)$. The first response of initial PLBs was only observed after 2 to 3 weeks of culture. It consisted of swelling of the initial protocorms and the formation of globular structures. The nodular structures from the swelling regions appeared after 3 weeks of culture, and these nodular tissues eventually developed further and formed PLBs. The results of this experiment showed that PLB multiplication in $P$. gigantea was highly influenced by the concentrations of chitosan and TDZ as well as medium composition. Varying concentrations of chitosan and TDZ in both media showed dissimilarities in development and proliferation of $P$. gigantea PLBs. The formation of PLBs was observed in all treatments, including the control media. The highest number of PLBs was obtained from primary PLBs cultured on NDM containing $10 \mathrm{mg} \cdot \mathrm{L}^{-1}$ chitosan in combination with $0.1 \mathrm{mg} \cdot \mathrm{L}^{-1} \mathrm{TDZ}$ with a mean number of 353 PLBs formed after 20 weeks of culture (Figs. 1B and 2). Conversely, basal NDM (control) and VW containing $20 \mathrm{mg} \cdot \mathrm{L}^{-1}$ chitosan and $0.5 \mathrm{mg} \cdot \mathrm{L}^{-1} \mathrm{TDZ}$ had the lowest PLBs with mean number of PLBs of 58 and 61, respectively (Fig. 2). The addition of $10 \mathrm{mg} \cdot \mathrm{L}^{-1}$ chitosan gave a significant increase in PLB proliferation in both media compared with the rest of TDZ-free cultures with the mean number of 237 and 214 PLBs in VW and NDM, respectively. It has been also observed that supplementation with $0.1 \mathrm{mg} \cdot \mathrm{L}^{-1} \mathrm{TDZ}$ was more effective for PLB proliferation when compared with the rest of chitosan-free treatments. Regardless of the effect of chitosan and TDZ supplementation on PLB proliferation, the basal solid VW was more effective for PLB multiplication compared with basal NDM (control). Although there was no specific pattern in PLB proliferation, the combination of $10 \mathrm{mg} \cdot \mathrm{L}^{-1}$ chitosan and $0.1 \mathrm{mg} \cdot \mathrm{L}^{-1}$

Table 2. Effect of chitosan and TDZ combination $\left(\mathrm{mg} \cdot \mathrm{L}^{-1}\right)$ on total fresh weight of PLBs after 20 weeks of cultivation in solid NDM and VW medium.

\begin{tabular}{rlcc}
\hline \multicolumn{2}{c}{ Treatment $\left(\mathrm{mg} \cdot \mathrm{L}^{-1}\right)$} & & \\
\cline { 1 - 2 } Chitosan & TDZ & Fresh wt $(\mathrm{g})(\mathrm{NDM})$ & Fresh wt $(\mathrm{g})(\mathrm{VW})$ \\
\hline 0 & 0 & $0.8 \pm 0.04 \mathrm{o}^{\mathrm{z}}$ & $1.5 \pm 0.1 \mathrm{fgh}$ \\
0 & 0.1 & $2.8 \pm 0.1 \mathrm{~cd}$ & $2.4 \pm 0.1 \mathrm{de}$ \\
0 & 0.5 & $1.2 \pm 0.1 \mathrm{jklm}$ & $1.3 \pm 0.14 \mathrm{ijklm}$ \\
5 & 0 & $1.2 \pm 0.1 \mathrm{jklm}$ & $1.2 \pm 0.14 \mathrm{jklm}$ \\
5 & 0.1 & $1.4 \pm 0.1 \mathrm{fghij}$ & $2.3 \pm 0.1 \mathrm{e}$ \\
5 & 0.5 & $1.1 \pm 1 \mathrm{jklm}$ & $2.5 \pm 0.1 \mathrm{de}$ \\
10 & 0 & $3.3 \pm 0.1 \mathrm{bc}$ & $3.4 \pm 0.1 \mathrm{bc}$ \\
10 & 0.1 & $4.8 \pm 0.1 \mathrm{a}$ & $3.8 \pm 0.1 \mathrm{~b}$ \\
10 & 0.5 & $3.5 \pm 0.2 \mathrm{~b}$ & $1.3 \pm 0.06 \mathrm{hijk}$ \\
15 & 0 & $1.6 \pm 0.1 \mathrm{fg}$ & $0.8 \pm 0.02 \mathrm{no}$ \\
15 & 0.1 & $1.3 \pm 0.05 \mathrm{ghij}$ & $1.2 \pm 0.16 \mathrm{lmn}$ \\
15 & 0.5 & $1.1 \pm 0.1 \mathrm{jklm}$ & $1.5 \pm 0.13 \mathrm{fghi}$ \\
20 & 0 & $1.3 \pm 0.1 \mathrm{hijk}$ & $1.3 \pm 0.1 \mathrm{hijk}$ \\
20 & 0.1 & $1.6 \pm 0.2 \mathrm{fg}$ & $1.6 \pm 0.07 \mathrm{fg}$ \\
20 & 0.5 & $1.0 \pm 0.02 \mathrm{mn}$ & $0.6 \pm 0.01 \mathrm{p}$ \\
25 & 0 & $1.1 \pm 0.04 \mathrm{jklm}$ & $1.2 \pm 0.15 \mathrm{jklm}$ \\
25 & 0.1 & $1.1 \pm 0.7 \mathrm{klm}$ & $1.1 \pm 0.06 \mathrm{jklm}$ \\
25 & 0.5 & $1.1 \pm 0.6 \mathrm{jklm}$ & $1.7 \pm 0.1 \mathrm{f}$ \\
\hline
\end{tabular}

${ }^{\mathrm{z}}$ Means followed by different letters within a column and row exhibited significant differences at $5 \%$ level according to Duncan's multiple range tests.

$\mathrm{TDZ}=$ thidiazuron; PLBs = protocorm-like bodies; NDM = New Dogashima medium; VW $=$ Vacin and Went.

TDZ was most effective for PLB multiplication on both media. NDM was found to be more responsive to the combination effect of chitosan and TDZ on PLB proliferation compared with VW medium (Fig. 2). Total fresh weight of PLBs was recorded at the initial stage and 20 weeks after culture initiation and significant differences were observed in the fresh weights of PLBs produced in all treatments compared with the initial stage. After 20 weeks of culture, NDM containing $10 \mathrm{mg} \cdot \mathrm{L}^{-1}$ chitosan and $0.1 \mathrm{mg} \cdot \mathrm{L}^{-1} \mathrm{TDZ}$ showed a stimulated 6-fold increase in fresh weight of PLBs compared with the weight of PLBs obtained in chitosan and TDZ-free NDM (Table 2).

Effect of chitosan and TDZ combination on shoot formation. The type of media used and the concentrations of chitosan and TDZ significantly affected the conversion of $P$. gigantea PLBs to shoots during the 20 weeks of culture. Small and round PLBs differentiated into mature PLBs with a profusion of leaves on the apical region and the tiny plantlets started to develop from the green PLBs after 10 weeks of culture. After a culture period of 20 weeks, the number of plantlets on each culture was recorded. The conversion of PLBs to shoots occurred in all treatment including basal VW and NDM. The best responses for shoot regeneration were observed in the treatments including VW with $10 \mathrm{mg} \cdot \mathrm{L}^{-1}$ chitosan in combination with 0.5 $\mathrm{mg} \cdot \mathrm{L}^{-1}$ TDZ (16), VW supplemented with $20 \mathrm{mg} \cdot \mathrm{L}^{-1}$ chitosan $(15)$, and VW with 15 $\mathrm{mg} \cdot \mathrm{L}^{-1}$ chitosan and $0.5 \mathrm{mg} \cdot \mathrm{L}^{-1} \mathrm{TDZ}(13)$ (Figs. 1C-D and 3). NDM in combination with $20 \mathrm{mg} \cdot \mathrm{L}^{-1}$ chitosan and $0.1 \mathrm{mg} \cdot \mathrm{L}^{-1} \mathrm{TDZ}$ or NDM with $5 \mathrm{mg} \cdot \mathrm{L}^{-1}$ chitosan exhibited the lowest number of shoots after 20 weeks (Fig. 3). Overall, the results on shoot formation showed that VW was more responsive than NDM either alone or in combination with chitosan and TDZ.

Assessment of variation using ISSR anal$y$ sis. The genetic stability was detected among initial PLBs (mother plant) and PLBs obtained from each subculture stage of solid NDM supplemented with $10 \mathrm{mg} \cdot \mathrm{L}^{-1}$ chitosan and $0.1 \mathrm{mg} \cdot \mathrm{L}^{-1} \mathrm{TDZ}$ (the optimal treatment for PLB proliferation). Among the 10 primers used for initial screening, eight ISSR primers provided clear and easy-to-score amplification products in all samples. The number of bands 


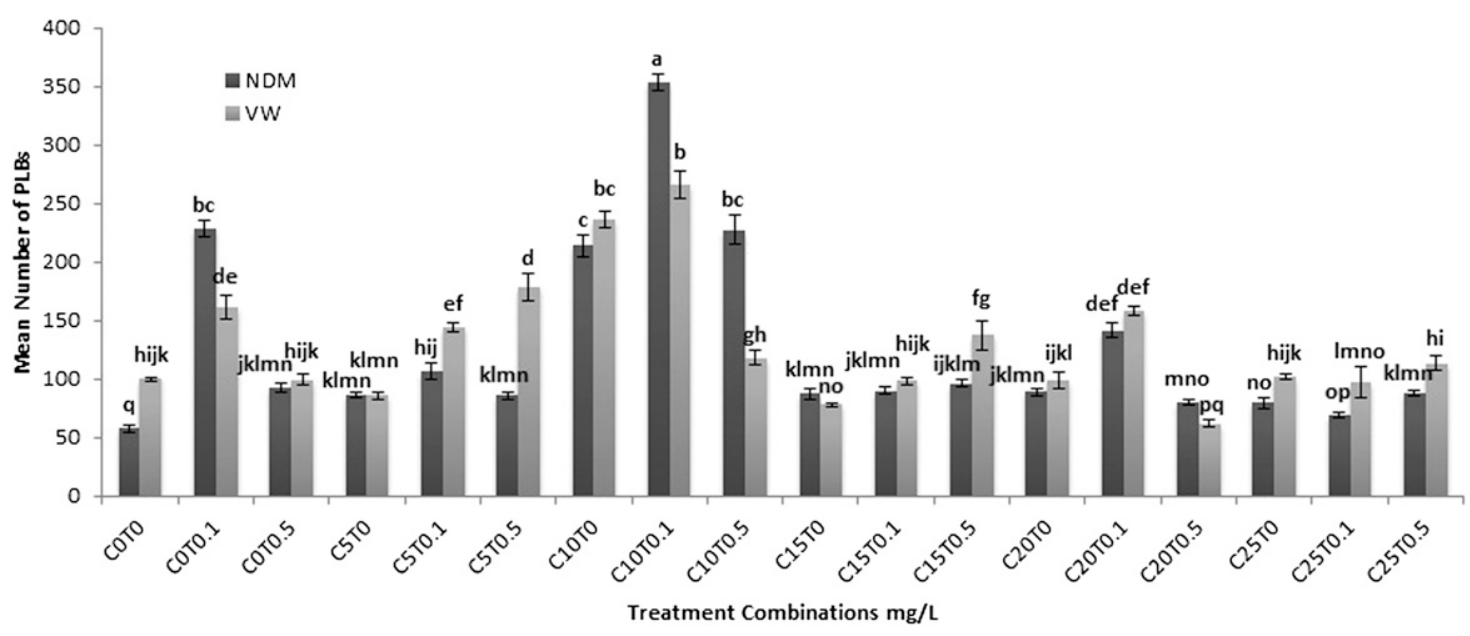

Fig. 2. Effect of chitosan and thidiazuron (TDZ)combinations $\left(\mathrm{mg} \cdot \mathrm{L}^{-1}\right)$ on mean number of protocorm-like bodies (PLBs) after 20 weeks of cultivation in solid New Dogashima medium (NDM)and Vacin and Went (VW) medium (SE was calculated from five independent experiments by one-way analysis of variance). $\mathrm{C}=$ chitosan; $\mathrm{T}=\mathrm{TDZ}$.

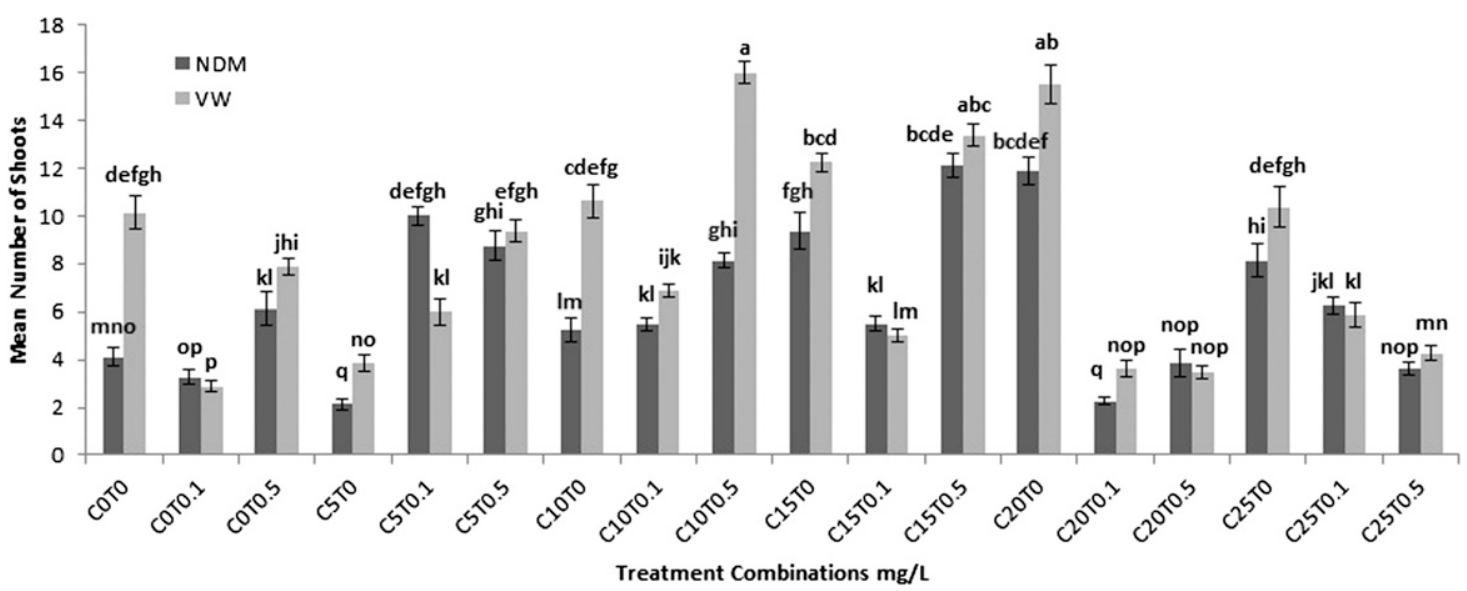

Fig. 3. Effect of chitosan and thidiazuron (TDZ) combinations $\left(\mathrm{mg} \cdot \mathrm{L}^{-1}\right)$ on mean number of shoots after 20 weeks of cultivation in solid New Dogashima medium (NDM)and Vacin and Went (VW) medium ( $\mathrm{SE}$ was calculated from five independent experiments by one-way analysis of variance). $\mathrm{C}=\mathrm{chitosan} ; \mathrm{T}=\mathrm{TDZ}$.

for each primer varied from five for primers I74 and UBC812 to 13 for primer T05 (Table 1). A total of 67 scorable bands was successfully generated with an average of 8.37 bands per primer, 56 monomorphic and 11 polymorphic bands with $16.41 \%$ polymorphism (Table 3 ). The highest number of polymorphic bands (three) was obtained by primers I65 and I2 with $27.3 \%$ polymorphism. In contrast, primers UBC842, UBC812, and I74 resulted in $0 \%$ polymorphism. All eight primers produced a unique set of amplification products ranging between 209 and $3742 \mathrm{bp}$. A total number of 343 amplified fragments was obtained using all primers. The ISSR amplification pattern of six samples from different subcultures of $P$. gigantea PLBs was represented by gel profiles of primers UBC 834 and I2 (Fig. 4). Eleven additional bands from the MP were present in the two last subcultures of PLBs.

Genetic similarity and multivariate anal$y$ sis. The similarity coefficient among six samples of PLBs ranged from 0.80 to 1 . Based on the dendrogram, three main clusters were obtained from the six stages. Cluster 1 included mother plant and regenerants corresponding to subcultures 1,2 , and 3 , which had similarity at the coefficient level of 1 . Cluster 2 corresponded to subculture 4 with a similarity value of 0.95 , indicating a genetic difference between initial PLBs (MP) and PLBs from Subculture 4 was not remarkable. Meanwhile, Cluster 3 represented the multiplied PLBs corresponding to the last subculture (5), which showed similarity at the coefficient level of 0.80 with Cluster 1 . It also showed the highest divergence from MP. The results showed that MP and various subcultures (1, 2, and 3) gave the same ISSR profile, whereas Subcultures 4 and 5 were $95 \%$ and $80 \%$ similar to MP, respectively (Table 4; Fig. 5).

\section{Discussion}

Different factors such as media composition, concentration and combination of plant growth regulators, organic additives in growth media, and the type of carbon sources have been reported to affect the development and multiplication of PLBs (Latip et al., 2007; Murdad et al., 2006; Ng and Saleh, 2010; Park et al., 1996; Sopalun et al., 2010). Several studies on in vitro propagation of Phalaenopsis species and their hybrids through callus or PLBs have been presented (Liu et al., 2006; Murdad et al., 2006; Sinha et al., 2007). The positive effect of TDZ on PLB induction and proliferation has also been reported in different Phalaenopsis species (Hong et al., 2010; Khoddamzadeh et al., 2011). The efficiency of chitosan in PLB proliferation greatly depends on plant genotype, formulation of growth medium, and different concentrations, types, molecular weights, degree of deacetylation, and polymerization of chitosan (Limpanavech et al., 2003; Nge et al., 2006; Pornpienpakdee et al., 2010). It was recently reported that the inclusion of 10 to $20 \mathrm{mg} \cdot \mathrm{L}^{-1}$ of chitosan in solid culture was the most effective range for induction of new PLBs in Dendrobium (Pornpienpakdee et al., 2010). A previous study on PLB propagation of $P$. gigantea showed that NDM containing TDZ at the concentration range of 0.1 to $0.3 \mathrm{mg} \cdot \mathrm{L}^{-1}$ significantly increased the percentage of new PLBs up to $58 \%$ to $66 \%$ after 80 -d culture initiation (Latip et al., 2007). It was proposed 
Table 3. Summary of intersimple sequence repeat amplified products from six samples of $P$. gigantea PLBs

\begin{tabular}{lc}
\hline Distribution & ISSR \\
\hline Total bands scored & 67 \\
Number of monomorphic bands & 56 \\
Number of polymorphic bands & 11 \\
Percentage of polymorphism & 16.41 \\
Number of primers used & 8 \\
Average polymorphism per primer & 1.37 \\
Average number of fragments per primer & 8.37 \\
Size range of amplified fragments & $209-3742$ \\
\hline PLBs = protocorm-like bodies.
\end{tabular}

PLBs $=$ protocorm-like bodies.
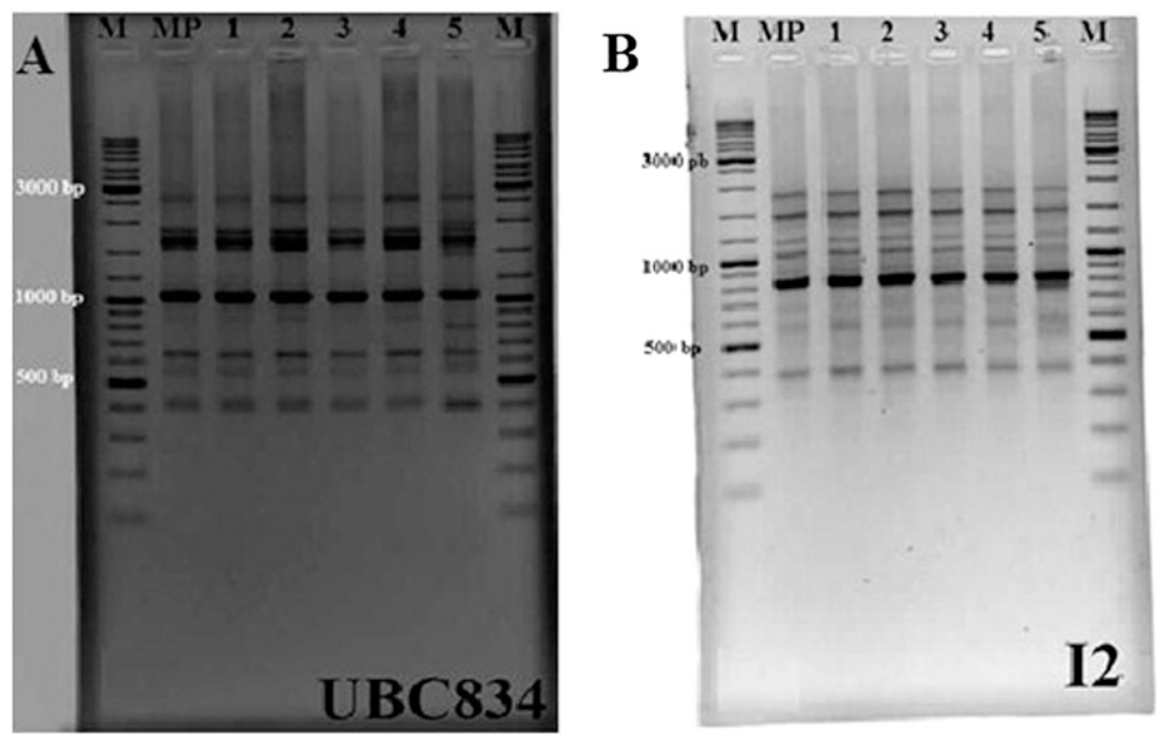

Fig. 4. Intersimple sequence repeat (ISSR) banding pattern in mother plants and multiplied protocorm-like bodies (PLBs)in New Dogashima medium (NDM)with $10 \mathrm{mg} \cdot \mathrm{L}^{-1}$ chitosan and $0.1 \mathrm{mg} \cdot \mathrm{L}^{-1}$ thidiazuron (TDZ) (lane MP is mother plant, lanes 1 to 5 are multiplied PLBs obtained after subcultures 1 to 5 with optimal chitosan).

Table 4. Similarity matrix of the somaclonal variation between mother plant and PLBs from different subcultures of optimum treatment.

\begin{tabular}{lllllll}
\hline Samples & MP & S1 & S2 & S3 & S4 & S5 \\
\hline MP & 1 & & & & & \\
S1 & 1 & 1 & & & & \\
S2 & 1 & 1 & 1 & & & \\
S3 & 1 & 1 & 1 & 1 & & \\
S4 & 0.95 & 0.95 & 0.95 & 0.95 & 1 & \\
S5 & 0.8 & 0.8 & 0.8 & 0.8 & 0.83 & 1 \\
\hline
\end{tabular}

that TDZ is the most compelling cytokinin for enhancing PLBs proliferation in Phalaenopsis species (Ernst, 1994). Widespread use of cytokinins either individually or in combination with auxins for induction and subsequent proliferation of PLBs have been reported (Khoddamzadeh et al., 2011; Naing et al., 2010). Nevertheless, the combination of chitosan and TDZ in semisolid media provides an alternative means for mass propagation of PLBs. This is attributed to the performance and role of chitosan in enhancing growth and development by stimulating a signaling pathway related to auxin biosynthesis (Uthairatanakij et al., 2007). The combination effect of chitosan and TDZ on PLB proliferation seems to be similar with the combination effect of cytokinins and auxins on PLB multiplication of some orchids (Naing et al., 2010; Niknejad, 2009). In a previous study on PLB multiplication of P.gigantea, NDM in combination with $1 \mathrm{mg} \cdot \mathrm{L}^{-1} \mathrm{NAA}$ and $0.1 \mathrm{mg} \cdot \mathrm{L}^{-1} \mathrm{TDZ}$ gave the highest percentage of new PLBs (Niknejad, 2009). The influence of different basal growth media on plant regeneration from PLBs has also been investigated by several researchers (Park et al., 2000; Sheelavantmath et al., 2005; Shimura and Koda, 2004).

In both media containing TDZ alone, the differentiation of PLBs to shoots was extremely low compared with the rest of the treatments (Fig. 3). However, it has been noted that the application of TDZ was efficient in shoot regeneration from PLBs of Epidendrum radicans (Chen et al., 2002), Vanda coerulea (Malabadi et al., 2004), and Dendrobium chrysotoxum (Roy et al., 2007). Therefore, the role of TDZ in shoot regeneration seems to be quite different among species. The results of the present experiment revealed that the presence of TDZ alone in growth medium might be effective only for PLB induction and proliferation of $P$. gigantea. The results showed that the combination of chitosan and TDZ was more efficient in shoot formation from PLBs. The conversion of PLBs into plantlets has often been reported to occur without the influence of PGRs (Hong et al., 2010) with very few expectations (Hossain et al., 2010; Tian et al., 2008). Interestingly, it was observed that the basal VW and NDM were also able to convert PLBs into plantlets, but in low numbers (Fig. 3). Chitosan alone at a concentration range of 5 to $15 \mathrm{mg} \cdot \mathrm{L}^{-1}$ showed a significant increase in shoot regeneration of Grammatophyllum speciosum in solid medium (Sopalun et al., 2010). It has been also reported that the most appropriate chitosan concentration for shoot induction of Dendrobium 'Eiskul' was 10 or $20 \mathrm{mg} \cdot \mathrm{L}^{-1}$ (Pornpienpakdee et al., 2010). In the present study, the combination of chitosan and TDZ significantly promoted the formation of shoots during the 20 weeks of culture. This is attributed to the performance of chitosan in enhancing growth and development of PLBs through signaling a pathway of auxin biosynthesis (Uthairatanakij et al., 2007) and the potential of TDZ in enhancing shoot regeneration from PLBs (Malabadi et al., 2004).

The occurrence of somaclonal variations during in vitro culture is common and frequencies have to be specified in relation to the type of growth stimulators and the subculture period. A previous study on PLB multiplication of $P$. gigantean in liquid culture showed that $10 \mathrm{mg} \cdot \mathrm{L}^{-1}$ chitosan produced the highest mean number of PLBs without somaclonal variation after 8 weeks of culture (Samarfard et al., 2013). In this study, the chitosan and TDZ combination in solid culture enhanced clonal propagation of PLBs with little somaclonal variation. However, increasing the number of subculturing cycles during tissue culture may result in genetic variation. It has been previously reported that the use of potential plant growth regulators like TDZ in tissue culture could induce alteration(s) in sensitive regions of the plant genome (Sala et al., 1999). ISSR markers are considered suitable to determine somaclonal variations among plants produced by micropropagation (Joshi and Dhawan, 2007; Leroy et al., 2001). There are a few reports on somaclonal variation in Phalaenopsis in response to subculture cycles and tissue culture period.

In the present study, differences in the number of specific bands among the parent plants and PLBs of different subcultures indicated minimal genetic variations of the multiplied PLBs compared with the MP. Only 20\% dissimilarity was observed in PLB proliferation using $10 \mathrm{mg} \cdot \mathrm{L}^{-1}$ chitosan and $0.1 \mathrm{mg} \cdot \mathrm{L}^{-1} \mathrm{TDZ}$ after 20 weeks of culture. The occurrence of specific band/loci in donor plants (MP) and loss of it in the PLBs of last subcultures demonstrated the loss of certain loci during in vitro culture as a result of somaclonal variation. Meanwhile, the presence of specific band/loci in the induced PLBs from last subcultures and their absence in parent plants may denote the incidence of genetic modifications leading to formation of new binding sites in these plants. It has been previously reported that dissimilarity among PLBs of different subcultures in Phalaenopsis bellina as affected by TDZ 


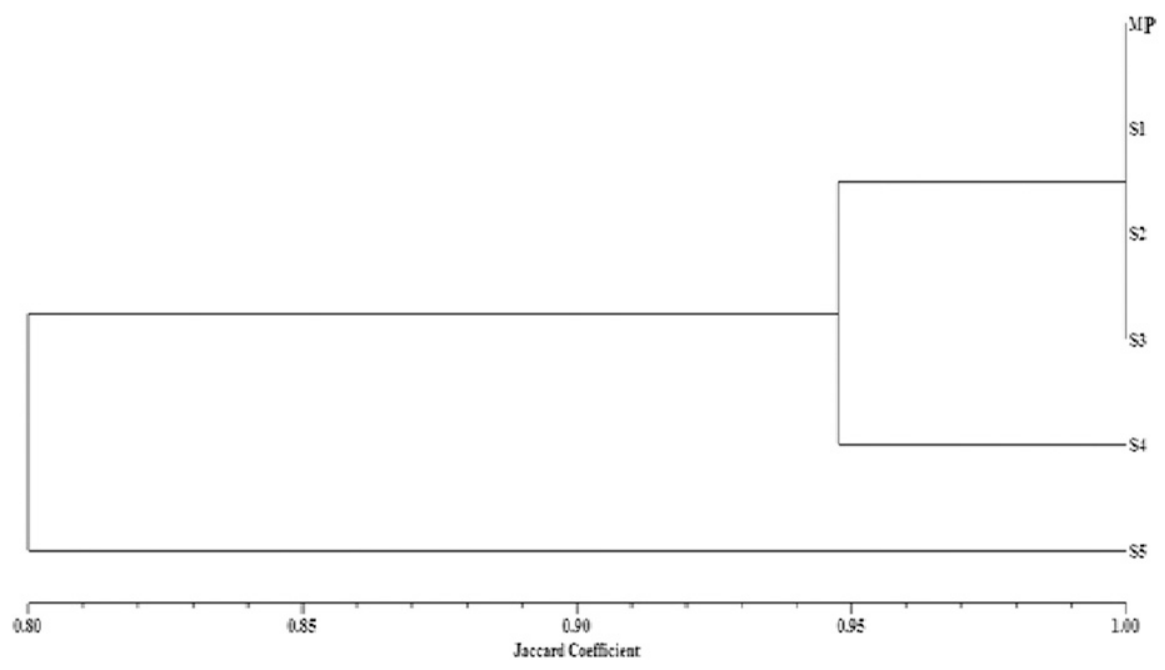

Fig. 5. Dendrogram exhibiting coefficient similarities among six samples from different subcultures of P. gigantea protocorm-like bodies (PLBs) [unweighted pair group method with arithmetic average (UPGMA) cluster analysis (NTSYS) of the intersimple sequence repeat (ISSR) profiles derived from eight primers using Jaccard's similarity coefficient; MP corresponding to mother plant and S corresponding to subcultures 1 to 5$]$.

was only $17 \%$ compared with the MP (Khoddamzadeh et al., 2010). Tokuhara (1992) also investigated the phenotypes and genetic variations among the different clones of Phalaenopsis and had indicated that $\approx 10 \%$ variation was present among the various clones.

\section{Conclusion}

In summary, the present study has emphasized on the establishment of an in vitro protocol for PLB proliferation of Phalaenopsis gigantea using different growth media supplemented with chitosan and TDZ. The results of this study has shown that after 20 weeks of culture, the combination of $10 \mathrm{mg} \cdot \mathrm{L}^{-1}$ chitosan and $0.1 \mathrm{mg} \cdot \mathrm{L}^{-1} \mathrm{TDZ}$ in NDM induced the highest mean number of PLBs (353) and a 19-fold increase in fresh weight of PLBs when compared with the weight of PLBs at the start of the experiment. The best response for shoot regeneration was observed in treatments of VW with $10 \mathrm{mg} \cdot \mathrm{L}^{-1}$ chitosan in combination with $0.5 \mathrm{mg} \cdot \mathrm{L}^{-1} \mathrm{TDZ}(16)$, VW supplemented with $20 \mathrm{mg} \cdot \mathrm{L}^{-1}$ chitosan (15), and VW with $15 \mathrm{mg} \cdot \mathrm{L}^{-1}$ chitosan and $0.5 \mathrm{mg} \cdot \mathrm{L}^{-1}$ TDZ (13). In general, the combination of chitosan and TDZ in solid VW medium was more responsive than in NDM in terms of producing higher quantity of shoots. In this study, somaclonal variation estimated among mother plant and PLBs induced from different subcultures of the optimum treatment (NDM supplemented with $10 \mathrm{mg} \cdot \mathrm{L}^{-1}$ chitosan and $0.1 \mathrm{mg} \cdot \mathrm{L}^{-1} \mathrm{TDZ}$ ) showed minimal or no changes occurred between mother plant and the PLBs obtained after 16 weeks of culture. A $20 \%$ dissimilarity was observed between MP and produced PLB after 20 weeks of culture. Therefore, PLB proliferation of Phalaenopsis gigantea in solid NDM supplemented with $10 \mathrm{mg} \cdot \mathrm{L}^{-1}$ chitosan and $0.1 \mathrm{mg} \cdot \mathrm{L}^{-1} \mathrm{TDZ}$ can be carried out successfully for 16 weeks, whereas further proliferation may result in the occurrence of somaclonal variation and morphological changes.

\section{Literature Cited}

Arditti, J. and R. Ernest. 1993. Micropropagation of orchid. John Wiley and Sons, New York, NY.

Chai, M.L., C.J. Xu, K.K. Senthil, J.Y. Kim, and D.H. Kim. 2002. Stable transformation of protocorm-like bodies in Phalaenopsis orchid mediated by Agrobacterium tumefaciens. Sci. Hort. 96:213-224.

Chen, L.R., J.T. Chen, and W.C. Chang. 2002. Efficient production of protocorm-like bodies and plant regeneration from flower stalk explants of the sympodial orchid Epidendrum radicans. In Vitro Cell. Dev. Biol. Plant 38:441-445.

Cote, F.X., J.A. Sandoval, P. Marie, and E. Auboiron. 1993. Variations in micropropagated bananas and plantains. Literature survey. Fruits $48: 15-22$.

Devarumath, R.M., S. Nandy, V. Rani, S. Marimuthu, N. Muraleedharan, and S.N. Raina. 2002. RAPD, ISSR and RFLP fingerprints as useful markers to evaluate genetic integrity of micropropagated plants of three diploid and triploid elite tea clones representing Camellia sinensis (China type) and C. assamica ssp. assamica (AssamIndia type). Plant Cell Rpt. 21:166-173.

Doyle, J.J. and J.L. Doyle. 1990. Isolation of plant DNA from fresh tissue. Focus 12:13-15.

Ernst, R. 1994. Effect of thidiazuron on in vitro propagation of Phalaenopsis and Doritaenopsis (Orchidaceae). Plant Cell Tissue Organ Cult. 39:273-275

Hong, P.I., J.T. Chen, and W.C. Chang. 2010. Shoot development and plant regeneration from protocorm-like bodies of Zygopetalum mackayi. In Vitro Cell. Dev. Biol. Plant 46:306-311.

Hossain, M.M., M. Sharma, J.A. Teixeira da Silva, and P. Pathak. 2010. Seed germination and tissue culture of Cymbidium giganteum Wall. ex Lind1. Sci. Hort. 123:479-487.

Ishii, Y., T. Takamura, M. Goi, and M. Tanaka. 1998. Callus induction and somatic embryogenesis of Phalaenopsis. Plant Cell Rpt. 17:446450 .
Joshi, P. and V. Dhawan. 2007. Assessment of genetic fidelity of micropropagated Swertia chirayita plantlets by ISSR marker assay. Biol. Plant. 51:22-26.

Khoddamzadeh, A., U. Sinniah, M. Kadir, S. Kadzimin, M. Mahmood, and S. Sreeramanan. 2010. Detection of somaclonal variation by random amplified polymorphic DNA analysis during micropropagation of Phalaenopsis bellina (Rchb.f.) Christenson. Afr. J. Biotechnol. 9:6632-6639.

Khoddamzadeh, A., U. Sinniah, M. Kadir, S Kadzimin, M. Mahmood, and S. Sreeramanan. 2011. In vitro induction and proliferation of protocorm-like bodies (PLBs) from leaf segments of Phalaenopsis bellina (Rchb.f.) Christenson. Plant Growth Regulat. 65:381-387.

Lakshmanan, V., R.V. Sreedhar, and N. Bhagyalakshmi. 2007. Molecular analysis of genetic stability in long term micropropagated shoots of banana using RAPD and ISSR markers. Electron. J. Biotechnol. 10:1-8.

Latip, M., R. Murdad, Z.A. Aziz, L.H. Ting, L.M. Govindasamy, and R. Ripin. 2007. Effects of N6-benzyladenine and thidiazuron on proliferation of Phalaenopsis gigantea protocorms. Proc. Asia Pacific Conference on Plant Tissue and Agribiotechnology. 18:217-220.

Leroy, X.J., K. Leon, J.M. Hily, P. Chaumeil, and M. Branchard. 2001. Detection of in vitro culture-induced instability through inter-simple sequence repeat analysis. Theor. Appl. Genet. 102:885-891.

Liau, C.H., S.J. You, V. Prasad, H.H. Hsiao, J.C. Lu, N.S. Yang, and M.T. Chan. 2003. Agrobacterium tumefaciens-mediated transformation of an Oncidium orchid. Plant Cell Rep. 21:993-998.

Limpanavech, P., R. Pichyangkura, C. Khunwasi, S. Chadchawan, P. Lotrakul, P. Bunjongrat, A. Chaidee, and T. Akaraeakpanya. 2003. The effects of polymer type, concentration and $\%$ DD of bicatalyte modified chitosan on flora production of Dendrobium 'Eiskul'. National chitin-chitosan conference, Chulalongkorn University, Bangkok, Thailand, 17-18 July 2003. p. 60-64.

Liu, T.A., J.J. Lin, and R.Y. Wu. 2006. The effects of using trehalose as a carbon source on the proliferation of Phalaenopsis and Doritaenopsis protocorm-like bodies. Plant Cell Tissue Organ Cult. 86:125-129.

Malabadi, R.B., G.S. Mulgund, and K. Nataraja. 2004. Efficient regeneration of Vanda coeru$l e a$, an endangered orchid using thidiazuron. Plant Cell Tissue Organ Cult. 76:289-293.

Murdad, R., K.S. Hwa, C.K. Seng, M.A. Latip, Z.A. Aziz, and R. Ripin. 2006. High frequency multiplication of Phalaenopsis gigantea using trimmed bases protocorms technique. Sci. Hort. 111:73-79.

Naing, A., J. Chung, I. Park, and K. Lim. 2010. Efficient plant regeneration of the endangered medicinal orchid, Coelogyne cristata using protocorm-like bodies. Acta Physiol. Plant. 33: 659-666.

Nash, N. 2003. Phalaenopsis primer: a beginner's guide to growing moth orchids. Orchids. 72 : 906-913.

$\mathrm{Ng}, \mathrm{C}$.Y. and N. Saleh. 2010. In vitro propagation of Paphiopedilum orchid through formation of protocorm-like bodies. Plant Cell Tissue Organ Cult. 105:193-202.

Nge, K.L., N. New, S. Chandrkrachang, and W.F. Stevens. 2006. Chitosan as a growth stimulator in orchid tissue culture. Plant Sci. 170:1185-1190.

Niknejad, A. 2009. Determination of genetic relationships among Phalaenopsis spp. using random 
amplified polymorphic DNA and in vitro propagation of Phalaenopsis gigantea. Master's thesis, Universiti Putra Malaysia.

Niknejad, A., M.A. Kadir, and S.B. Kadzimin. 2011. In vitro plant regeneration from protocorms like bodies (PLBs) and callus of Phalaenopsis gigantea (Epidendroideae:Orchidaceae). Afr. J. Biotechnol. 10:11808-11816.

Park, S.Y., S. Kakuta, A. Kano, and M. Okabe. 1996. Efficient propagation of protocorm-like bodies of Phalaenopsis in liquid medium. Plant Cell Tissue Organ Cult. 45:79-85.

Park, S.Y., H.N. Murthy, and K.Y. Paek. 2000. Mass multiplication of protocorm-like bodies using bioreactor system and subsequent plant regeneration in Phalaenopsis. Plant Cell Tissue Organ Cult. 63:67-72.

Pornpienpakdee, P., R. Singhasurasak, P. Chaiyasap, R. Pichyangkura, R. Bunjongrat, S. Chadchawan, and P. Limpanavech. 2010. Improving the micropropagation efficiency of hybrid Dendrobium orchids with chitosan. Sci. Hort. 124: 490-499.

Rodrigues, K. and S. Kumar. 2009. Isolation and characterization of microsatellite loci in Phalaenopsis gigantea. Conserv. Genet. 10:559-562.

Rohlf, F.J. 1993. NTSYS-pc, numerical taxonomy and multivariate analysis system. Version 1.80. Exeter Software, Setauket, NY.

Roy, J., S. Naha, M. Majumdar, and N. Banerjee. 2007. Direct and callus mediated protocormlike body induction from shoot-tips of Dendrobium chrysotoxum Lindl. (Orchidaceae). Plant Cell Tissue Organ Cult. 90:31-33.

Sala, F., A. Arencibia, S. Castiglione, P. Christou, Y. Zheng, and Y. Han. 1999. Molecular and field analysis of somaclonal variation in transgenic plants, p. 259-262. In: Altman, A., M. Ziv, and S. Izhar (eds.). Plant biotechnology and in vitro biology in the 21 st century. Kluwer, Dordrecht, The Netherlands.

Samarfard, S., M.A. Kadir, S.B. Kadzimin, and M.S. Halimi. 2013. Genetic stability of in vitro multiplied Phalaenopsis gigantea protocormlike bodies as affected by chitosan. Not Bot Hort Agrobot Cluj. 41:177-183.

Sheelavantmath, S.S., H.N. Murthy, B.P. Hema, E.J. Hahn, and K.Y. Paek. 2005. High frequency of protocorm like bodies (PLBs) induction and plant regeneration from protocorm and leaf sections of Aerides crispum. Sci. Hort. 106:395-401.

Shimura, H. and Y. Koda. 2004. Micropropagation of Cypripedium macranthos var. rebunense through protocorm-like bodies derived from mature seeds. Plant Cell Tissue Organ Cult. 78:273-276.

Shu-guo, F. 2008. Tissue culture system of Phalaenopsis in genetic transformation. J. Biotechnol. 136:164-165.

Sinha, P., M.L. Hakim, and M.F. Alam. 2007. Efficient micropropagation of Phalaenopsis amabilis (L.) BL. cv. 'Cool Breeze' using inflorescence axis thin sections as explants. Propag Ornam Plants 7:9-15.

Sopalun, K., K. Thammasiri, and K. Ishikawa. 2010. Micropropagation of the Thai orchid Grammatophyllum speciosum Blume. Plant Cell Tissue Organ Cult. 101:143-150.

Sreeramanan, S., B. Vinod, S. Sashi, and R. Xavier. 2008. Optimization of the transient Gusa gene transfer of Phalaenopsis violacea orchid via Agrobacterium tumefaciens: An assessment of factors influencing the efficiency of gene transfer Mechanisms. Adv. in Nat. Appl. Sci. 2:77-88.

Thammasiri, K. 2002. Preservation of seeds of some Thai orchid species by vitrification. Proc. of the 16th World Orchid Conference. p. 248 251.

Tian, C., Y. Chen, X. Zhao, and L. Zhao. 2008. Plant regeneration through protocorm likebodies induced from rhizoids using leaf explants of Rosa spp. Plant Cell Rpt. 27:823831.

Tokuhara, K. 1992. Somaclonal variation of flowers in micropropagated plants through flower stalk bud culture. In: Ichihashi S, Nagata $\mathrm{H}$ (eds.). Proc Nagoya Int Orchid Show 92, Nagoya, Japan, pp. 317-319.

Tokuhara, K. and M. Mii. 1993. Micropropagation of Phalaenopsis and Doritaenopsis by culturing shoot tips of flower stalk buds. Plant Cell Rpt. 13:7-11.

Tokuhara, K. and M. Mii. 1998. Somaclonal variation in flower and inflorescence axis in micropropagated plants through flower stalk bud culture of Phalaenopsis and Doritaenopsis. Plant Biotechnol. 15:23-28.

Uthairatanakij, A., J.A. Teixeira da Silva, and K. Obi Wan. 2007. Chitosan for Improving Orchid Production and Quality. Orchid Sci Biotechnol. $1: 1-5$.

Vacin, E.F. and F.W. Went. 1949. Some pH changes in nutrient solutions. Bot. Gaz. 110: 605-613.

Zheng, Y.X., C.C. Chen, Y.K. Chen, and F.J. Jan. 2008. Identification and characterization of a potyvirus causing chlorotic spots on Phalaenopsis orchids. Eur. J. Plant Pathol. 121: 87-95. 